\title{
(2) OPEN ACCESS \\ Incidence, nature and causes of avoidable significant harm in primary care in England: retrospective case note review
}

- Additional material is published online only. To view, please visit the journal online (http://dx.doi.org/10.1136/ bmjqs-2020-011405).

For numbered affiliations see end of article.

\section{Correspondence to} Professor Anthony J Avery, Division of Primary Care, University of Nottingham Faculty of Medicine and Health Sciences, Nottingham, Nottingham, UK;

tony.avery@nottingham.ac.uk

Received 25 April 2020 Revised 25 August 2020 Accepted 12 September 2020

Check for updates

(c) Author(s) (or their employer(s)) 2020. Re-use permitted under CC BY-NC. No commercial re-use. See rights and permissions. Published by BMJ.

To cite: Avery AJ, Sheehan C, Bell B, et al. BMJ Qual Saf Epub ahead of print: [please include Day Month Year]. doi:10.1136/

bmjqs-2020-011405

\author{
Anthony J Avery (D , , ${ }^{1,2}$ Christina Sheehan, ${ }^{1}$ Brian Bell, ${ }^{1}$ \\ Sarah Armstrong, ${ }^{3}$ Darren M Ashcroft, ${ }^{2,4}$ Matthew J Boyd (D) , \\ Antony Chuter, ${ }^{1}$ Alison Cooper, ${ }^{6}$ Ailsa Donnelly, ${ }^{1}$ Adrian Edwards, ${ }^{6}$ \\ Huw Prosser Evans, ${ }^{6}$ Stuart Hellard ${ }^{6}$ Joanne Lymn, ${ }^{7}$ Rajnikant Mehta, ${ }^{8}$ \\ Sarah Rodgers, ${ }^{9}$ Aziz Sheikh (D) , ${ }^{10}$ Pam Smith, ${ }^{11}$ Huw Williams, ${ }^{6}$ \\ Stephen M Campbell, ${ }^{2,12}$ Andrew Carson-Stevens ${ }^{6}$
}

\section{ABSTRACT}

Objective To estimate the incidence of avoidable significant harm in primary care in England; describe and classify the associated patient safety incidents and generate suggestions to mitigate risks of ameliorable factors contributing to the incidents.

Design Retrospective case note review. Patients with significant health problems were identified and clinical judgements were made on avoidability and severity of harm. Factors contributing to avoidable harm were identified and recorded.

Setting Primary care.

Participants Thirteen general practitioners (GPs) undertook a retrospective case note review of a sample of 14407 primary care patients registered with 12 randomly selected general practices from three regions in England (total list size: 92255 patients).

Main outcome measures The incidence of significant harm considered at least 'probably avoidable' and the nature of the safety incidents.

Results The rate of significant harm considered at least probably avoidable was 35.6 ( $95 \% \mathrm{Cl} 23.3$ to 48.0$)$ per 100000 patient-years $(57.9,95 \% \mathrm{Cl} 42.2$ to 73.7 , per 100000 based on a sensitivity analysis). Overall, 74 cases of avoidable harm were detected, involving 72 patients. Three types of incident accounted for more than $90 \%$ of the problems: problems with diagnosis accounted for $45 / 74$ (60.8\%) primary incidents, followed by medication-related problems $(n=19,25.7 \%)$ and delayed referrals $(n=8,10.8 \%)$. In 59 (79.7\%) cases, the significant harm could have been identified sooner $(n=48)$ or prevented $(n=11)$ if the GP had taken actions aligned with evidence-based guidelines.

Conclusion There is likely to be a substantial burden of avoidable significant harm attributable to primary care in England with diagnostic error accounting for most harms. Based on the contributory factors we found, improvements could be made through more effective implementation of existing information technology, enhanced team coordination and communication, and greater personal and informational continuity of care.

\section{INTRODUCTION}

Healthcare-associated harm is an internationally recognised threat to public health and well-being. Across all income settings, as many countries aspire towards universal health coverage, attention has focused on the critical role of primary care-led healthcare systems to help achieve this goal. ${ }^{12}$ In countries like the UK, over $90 \%$ of clinical encounters are delivered in community settings, ${ }^{3}$ but a clear understanding of avoidable harm is needed to enable healthcare systems to identify and learn from the most serious incidents and the factors amenable to intervention.

Most patient safety research has focused on hospital-based care settings resulting in a greater awareness of the frequency and causes of health care-associated errors, and the resulting burden to patients. ${ }^{4}$ Patient safety research in primary care has been slower, ${ }^{25}$ although the profile of patient safety in primary care was provided a platform by the WHO's Safer Primary Care Expert Group (2012) and catalysed more recently by the US National Patient Safety Foundation's call to look 'beyond hospitals to the full care continuum' and the Organisation for Economic Co-operation and Development's assessment of the economic burden of unsafe primary and ambulatory care. ${ }^{6-8}$ The WHO's Technical Series for Safer Primary Care, where world experts have explored the existing evidence base for primary care safety, highlighted that major evidence gaps exist and robust high-quality epidemiological 
studies are needed to definitively establish the burden of unsafe primary care. ${ }^{9}$ While harm from hospitalbased care may be more visible, given the volume of patient consultations that occur in primary care, the aggregate burden of harm cannot be ignored.

Our WHO-commissioned systematic review investigating the frequency and burden of harm in general practice concluded $2 \%-3 \%$ of primary care encounters involved a patient safety incident, and around 1 in 25 of those resulted in a significant harm outcome that has a substantial impact on a patient's well-being. ${ }^{8}$ Included studies were notably heterogeneous in study design and definitions of outcome measures. None of the primary care studies in this, or our subsequent systematic review, ${ }^{10}$ reported the incidence of avoidable harm ${ }^{11} 12$ based on independent review of medical records, and few distinguished between minor and more significant harms. ${ }^{13}$ Also, we are aware of only one previous study that was large enough to identify substantial numbers of significant harms but did not report on these in detail. ${ }^{13}$ This means that based on the literature, it has not been possible to reliably quantify the overall burden of avoidable significant patient harm in primary care.

We have addressed this issue in the current study by undertaking a large retrospective case note review study using independent clinical reviewers to (1) estimate the incidence of avoidable significant harm in primary care in England; (2) quantify, describe and classify the patient safety incidents that result in avoidable significant harm (thus showing the top categories of avoidable harm) and (3) generate suggestions to mitigate risks of ameliorable factors that contributed to the incidents. Our study is different from other primary care studies because of its specific focus on identifying and understanding significant harm, and because it has estimated the incidence (rather than prevalence) of harm on the basis that this provides policy makers with a better idea of the potential burden of the problem. We have used a definition of avoidable harm based on a consensus study panel with general practitioners $(\mathrm{GPs})^{14}$ using real cases of unsafe general practice from our earlier national-level analysis of patient safety incident reports. ${ }^{15}$

\section{METHODS}

Our study protocol describes the methods we employed in detail, ${ }^{16}$ and an expanded version of our methods is in the online supplemental materials. Box 1 provides the definitions used in the study.

\section{Participants}

We used a stratified random sampling approach to invite general practices to participate from three different areas of England. We undertook a retrospective case note review of an open cohort of all primary care patients registered with participating general
Box 1 Definitions used in our study

\section{Significant harm}

Our definition of significant harm was informed by the international classification of patient safety definitions of moderate harm, severe harm and death outcomes. ${ }^{44}$ The definition used was as follows:

'A patient outcome is symptomatic, which required more intensive intervention than might otherwise have been required (eg, additional operative procedure) and resulted in an escalation of care (eg, hospital admission) or death. This caused a loss of function of at least one bodily organ, which may have been a temporary or permanent loss of its function'.

\section{Avoidability}

Our definition of avoidability was informed by our RAND/University of California Los Angeles appropriateness methods study ${ }^{14}$ to contextualise our definition of significant harm. The definition used was as follows:

'A patient safety incident could have probably, or totally been avoided by the timely intervention of a health care professional in family practice (eg, investigations, treatment, safety netting) and / or an administrative process (eg, referrals, alerts in electronic health records, procedures for following up results) in accordance with accepted standards of evidence-based practice and / or clinical governance and / or the Bolam test'. ${ }^{45}$

practices (between 1 April 2015 and 31 March 2016) to identify cases of avoidable significant harm.

\section{Recruitment and training of data collectors}

GPs with at least 5 years' experience in general practice were recruited to collect data from the participating practices and were provided with training. ${ }^{16}$

\section{Sampling of patient records}

We sampled patient records in three stages. In stage 1, we identified the total patient population of the practices at the start of the retrospective cohort (1 April 2015). In stage 2, we used electronic registry queries to identify patients at increased risk of significant health problems and/or avoidable significant harm (the 'enhanced sample'). Drawing on suggestions made by the research commissioners, the literature on avoidable harm in primary care ${ }^{8}$ and our own experience of analysing reports of harm associated with primary care, ${ }^{15}$ we included patients who had $\operatorname{died}^{17}$ been admitted to secondary care, ${ }^{18}$ were resident in a care home, ${ }^{19}$ had multimorbidity ${ }^{15}$ or polypharmacy, ${ }^{20} 21$ had undergone an invasive procedure in general practice $^{22}$ or had been certified unfit for work long term. In stage 3, one of the GP data collectors screened the electronic health record of each patient in the enhanced sample to identify any new significant health 
problems experienced by patients over the 12 months of the study (1 April 2015-31 March 2016). The GPs then undertook detailed retrospective reviews of the records of this final sample of patients to identify the extent to which errors in primary healthcare provision contributed to these problems.

For the purposes of sensitivity analysis (recognising that cases might have been missed by our sampling approach), the GP data collectors also undertook a detailed records review for the following:

- $2.5 \%$ random sample of the stage 1 population, not including patients identified for the stage 2 enhanced sample; each record was examined by a single GP reviewer.

- $10 \%$ random sample of the stage 2 enhanced sample; each record was examined by a second GP reviewer.

\section{Identification of avoidable significant harm and factors associated with this}

For those patients with significant health problems, the GP data collectors recorded whether they found any evidence of avoidable harm. If so, the GPs provided a detailed written account of the principal problem in the patient's primary care that led to the significant health problem, a narrative describing the manner in which the significant health problem could have potentially been prevented within primary care, and a judgement on the avoidability of the significant health problem using a validated 6-point scale (see table 1). ${ }^{1723}$ All cases were considered in detail by the study team, and the GP data collectors were asked to provide additional information if any clarification were needed. To ensure consistency, the study team made the final judgement, through consensus, in terms of the classification of avoidable significant harm.

\section{Data collection and coding}

Each of the participating general practices was visited by an informatician from the study team who collected baseline data on the practice population and ran a computer search to identify patients for the enhanced sample and for the sensitivity analyses. Using encrypted tablet computers and a virtual private network connection, the GP data collectors entered

\begin{tabular}{lll}
\hline Table 1 & Six-Point Avoidability & Scale $^{1723}$ \\
\hline Rating & Category & Description \\
\hline 1 & Totally unavoidable & Virtually no evidence of avoidability \\
2 & Unavoidable & $\begin{array}{l}\text { Slight to modest evidence of } \\
\text { avoidability }\end{array}$ \\
\hline 3 & Possibly avoidable & $\begin{array}{l}\text { Possibly avoidable, less than } 50-50, \\
\text { but close call }\end{array}$ \\
4 & Probably avoidable & $\begin{array}{l}\text { Probably avoidable, more than } \\
50-50, \text { but close call }\end{array}$ \\
5 & Probably avoidable & $\begin{array}{l}\text { Strong evidence of avoidability } \\
\text { Virtually certain evidence of } \\
\text { avoidability }\end{array}$ \\
\hline
\end{tabular}

anonymised data directly into a database on a secure server at Cardiff University. The nature of the avoidable harm was recorded by the GP data collectors using the comprehensive patient safety classification system developed in the Primary Care Patient Safety Classification study. ${ }^{24}$

\section{Analysis}

We estimated the incidence of significant harm that was considered at least probably avoidable (our primary outcome-avoidability score of 4 or more) and at least possibly avoidable (avoidability score 3 or more) accompanied by $95 \%$ CIs. ${ }^{16}$ We assessed interrater reliability of judgements made using the Cohen's kappa statistic (with 95\% CI).

Members of the study team then undertook a detailed analysis of the information provided on each case of potentially avoidable significant harm and included cases with at least 'slight to modest' (score or more) evidence of avoidability, as we judged that even in these cases there were important insights. We analysed the data recorded on the cases and examined the relationships between different types of incident and the factors that contributed to these incidents. As a result, we identified the most important factors contributing to avoidable significant harm.

\section{RESULTS}

Twelve practices were recruited (as shown in figure 1) and table 2 shows their characteristics compared with national averages for England. The practices were similar to the English average in terms of list size, Index of Multiple Deprivation, and age and gender of patients, but had a higher percentage of non-white patients. Also, all the participating practices were rated overall as 'good' or 'outstanding' by the Care Quality Commission (CQC), whereas almost $12 \%$ of the practices in England received 'inadequate' or 'requires improvement' scores.

The total list size for the 12 general practices at the start date of the study cohort (1 April 2015) was 92 255 (Stage 1). The total number of patient-years of clinical data available for the 92255 patients over the year of the cohort (1 April 2015-31 March 2016) was 89779.

The flow of patient records through the study is shown in figure 2 . The computer searches identified 12 080 patients $(13.1 \%)$ for the enhanced sample (stage 2 ). Their records were all examined by at least one GP data collector (first GP data collector in figure 2), and 1271 (10.5\% random sample) were examined independently by a second GP data collector. From the stage 1 population of 92255 , a random sample of $2327(2.5 \%)$ patients (but not included in the enhanced sample) was examined by one of the GP data collectors.

Based on the assessment of the GP data collector doing the first assessment on the enhanced sample, 


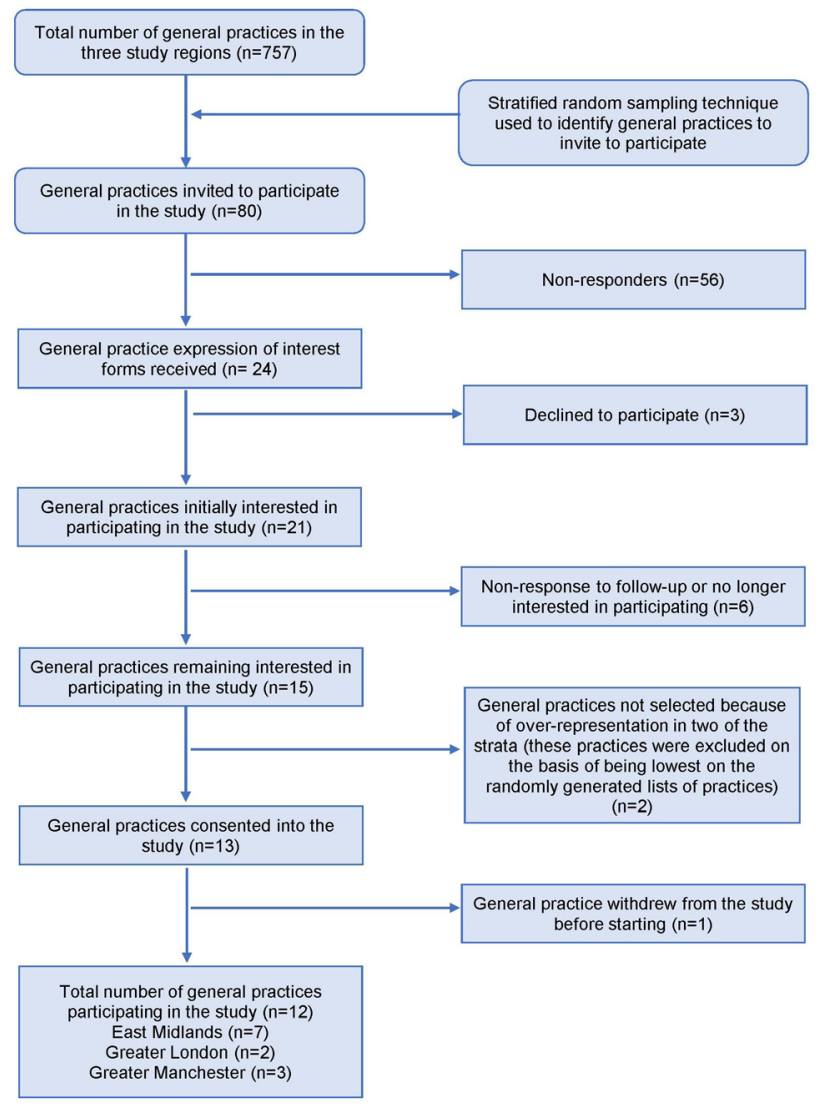

Figure 1 Flowchart showing how practices were recruited.

there were 2131 new significant health problems for 2116 patients between 1 April 2015 and 31 March 2016 (stage 3; see figure 2). For 2054 (96.4\%) of the significant health problems, the GP data collector judged that the patient had received an adequate standard of care and therefore classified these cases as having 'virtually no evidence of avoidability'.

For the remaining $77(3.6 \%)$ cases, the first GP reviewer formally assessed avoidability and the distribution of avoidability scores, following moderation by the study team, is shown in table 3. A further 10 cases had 'virtually no evidence of avoidability', meaning that in total, 2064 (96.9\%) of the 2131 significant health problems were considered unavoidable in primary care.

There were 32 cases $(1.5 \%)$ of significant harm considered to be at least probably avoidable and 51 (2.4\%) considered at least possibly avoidable. This translates into a rate of 35.6 per 100000 patient-years (95\% CI 23.3 to 48.0 ) for significant harm considered at least probably avoidable and 56.8 per 100000 patient-years (95\% CI 41.2 to 72.4 ) at least possibly avoidable.

\section{Sensitivity analysis}

The examination of the $2.5 \%$ sample of the patient population did not identify any additional cases of significant harm considered at least possibly avoidable. The examination of the $10 \%$ sample of the enhanced sample by a second GP reviewer identified two further cases of significant harm considered to be at least probably avoidable and four cases considered at least possibly avoidable, based on the final judgement of the study team. This means that had all the patient records in the enhanced sample been assessed independently by two GPs, there could have been an additional 20 cases considered at least probably avoidable, and 40 cases of significant harm considered at least possibly avoidable. In the sensitivity analysis, this translated into rates of 57.9 (95\% CI 42.2 to 73.7) per 100000 patient-years for significant harm considered at least probably avoidable, and 101.4 (95\% CI 80.5 to 122.2 ) per 100000 patient-years for significant harm considered at least possibly avoidable.

\section{Inter-rater reliability}

Where an assessment of avoidability was done, there was $77.0 \%$ agreement between GP data collectors and the study team about whether the case was considered at least possibly avoidable (Cohen's kappa: 0.49, 95\% CI 0.29 to 0.69 ). For the $10 \%$ sample of the enhanced sample, there was $71.5 \%$ agreement between the first and second GP reviewers that a patient had at least one significant health problem (kappa: 0.33, 95\% CI 0.27 to 0.38 ), and where an avoidability assessment was done independently by two GP data collectors, there was a $67.6 \%$ agreement about whether the significant harm was considered at least possibly avoidable (kappa: $0.34,95 \%$ CI: 0.02 to 0.66 ).

\section{Analysis of the nature and causes of avoidable significant harm}

For the detailed analysis of the nature and causes of avoidable significant harm, we included 74 cases involving 72 patients. The distribution of avoidability scores for these cases is shown in table 4 .

The distribution of different types of primary incidents for the 74 cases is shown in table 5 , with problems with diagnosis accounting for 60.8\%; medicationrelated problems for $25.7 \%$ and delayed referrals for $10.8 \%$ (the latter relating to situations where a clinician had decided that a referral was needed, but there was such a delay in the referral being made that the patient may have been harmed as a result). Examples of these incidents are shown in boxes 2 and 3. In relation to the 74 primary incidents, 114 underlying 'contributory factors' were identified, and these are shown in table 6. Patient factors accounted for $71.9 \%$, with comorbidities or multimorbidities being the most important categories $(24.6 \%$ of all contributory factors), while $17.5 \%$ of factors included issues such as not taking medicines as prescribed, problems with eliciting relevant information from patients or caregivers, not following medical advice and presenting with multiple issues in a single consultation. Factors such as multimorbidity and frailty contributed either through offering alternative explanations for symptoms or 


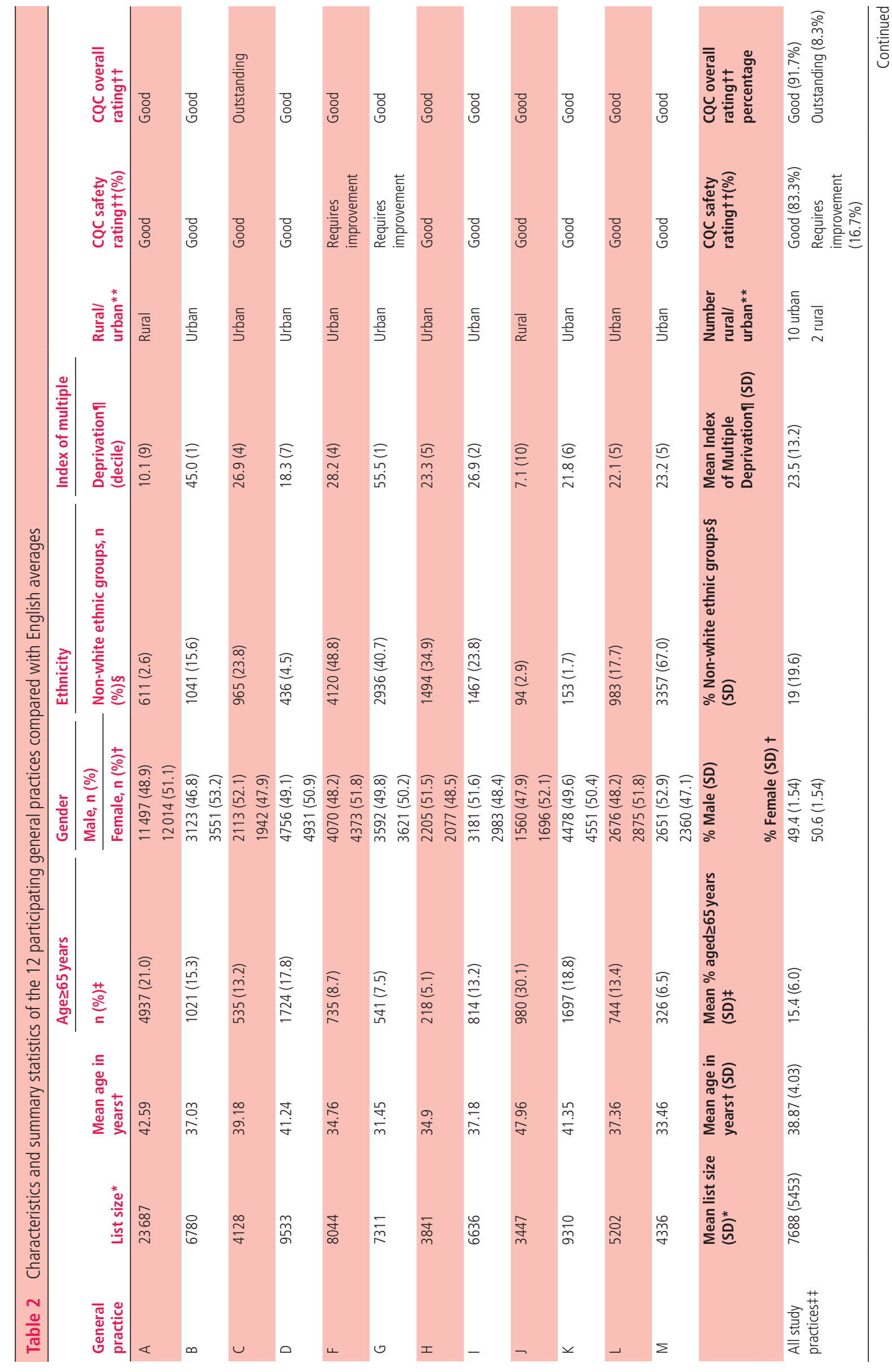




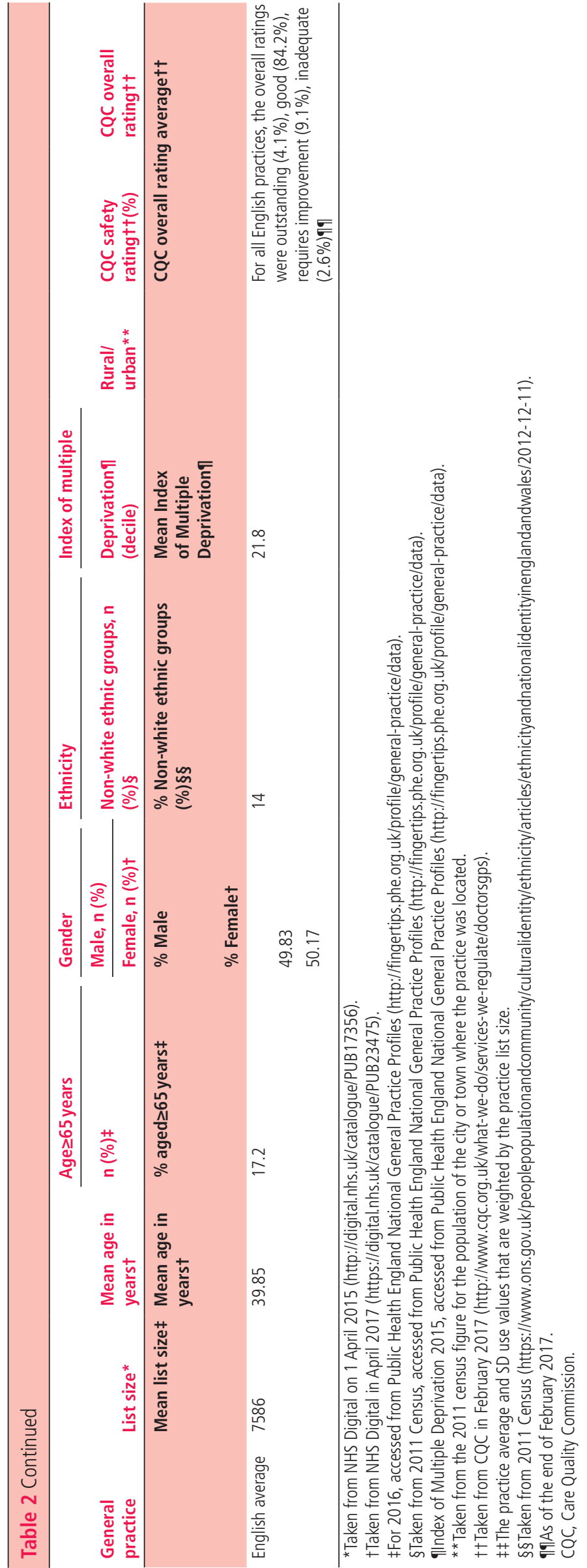

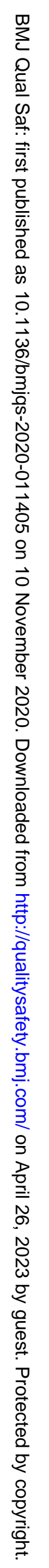




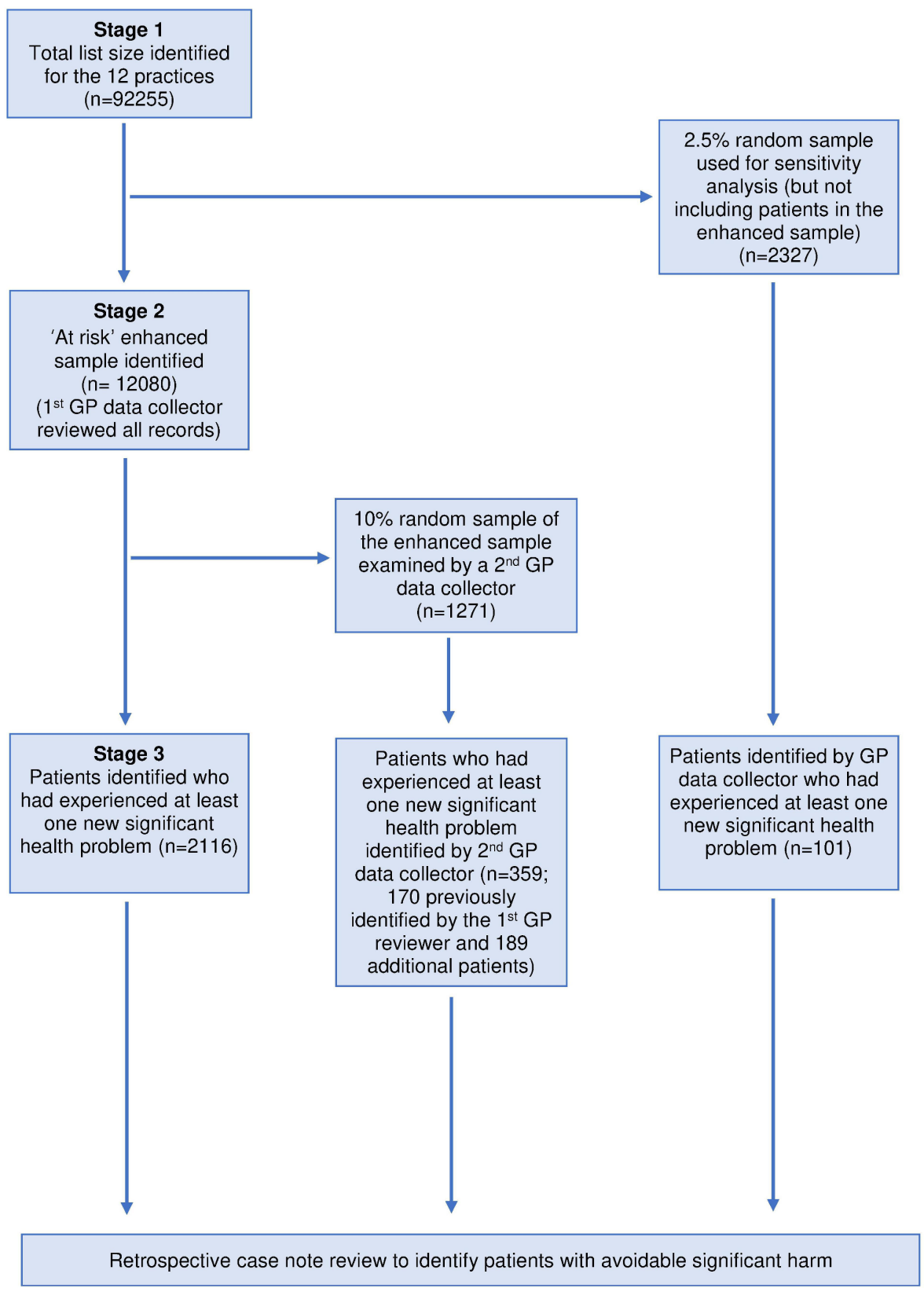

Figure 2 Stages of the study and flow of patient records through the study. GP, general practitioner.

by presenting clinicians with multiple competing demands. Organisational factors accounted for $21.1 \%$ of contributory factors, while staff factors such as inadequate knowledge, skills or mistakes by healthcare professionals accounted for 7.0\%. In 59 (79.7\%) of the 74 cases, the significant harm could have been identified sooner (48 cases) or prevented (11 cases) if the GP had taken actions aligned with evidence-based guidelines (see examples in box 2).

These 74 cases involved 115 healthcare professionals (81 (70.4\%) GPs and 10 (8.7\%) practice nurses), and only 4 of these $(3.5 \%)$ were clearly identifiable as being from outside the participating general practices (community nurse, community optometrist, community physiotherapist and community psychiatric nurse).

\section{DISCUSSION}

\section{Principal findings}

The estimated incidence of significant harm in English primary care considered at least 'probably' avoidable is between 35.6 and 57.9 per 100000 patient-years (the latter figure being based on sensitivity analysis). Extrapolating our findings to the English population of 55.6 million (mid-year 2017), we found that there are likely to be between 19800 and 32200 cases of 'probably avoidable' significant harm to patients each year.

The three major sources of significant avoidable harm in general practice were diagnostic error $(60.8 \%$ of the avoidable incidents), medication incidents (25.7\%) and delayed referrals (10.8\%). In $79.7 \%$ of cases, the 
Table 3 Avoidability of the 2131 new significant health problems identified by the first GP data collector

\begin{tabular}{lc}
\hline Avoidability classification & $\mathrm{n}(\%)$ \\
\hline $\begin{array}{l}\text { Totally avoidable: virtually certain evidence of } \\
\text { avoidability }\end{array}$ & $0(0.0)$ \\
\hline $\begin{array}{l}\text { Probably avoidable: strong evidence of avoidability } \\
\text { Probably avoidable: probably avoidable, }>50: 50, \text { but } \\
\text { close call }\end{array}$ & $18(0.7)$ \\
$\begin{array}{l}\text { Possibly avoidable: possibly avoidable, }<50: 50, \text { but close } \\
\text { call }\end{array}$ & $19(0.9)$ \\
$\begin{array}{l}\text { Unavoidable: slight to modest evidence of avoidability } \\
\text { Totally unavoidable: virtually no evidence of avoidability } \\
\text { (based on study team avoidability assessment) }\end{array}$ & $16(0.7)$ \\
$\begin{array}{l}\text { Totally unavoidable: virtually no evidence of avoidability } \\
\text { (based on GP assessment that there had been an }\end{array}$ & $2054(96.4)$ \\
'adequate standard of care') & \\
Total & $2131(100)$ \\
\hline GP, general practitioner. &
\end{tabular}

significant harm could have been identified sooner or prevented if the GP had taken actions aligned with evidence-based guidelines. The study identified a mix of organisational, clinician and patient contributory factors associated with the avoidable incidents. The majority of these were patient factors $(71.9 \%$ of the total contributory factors identified), including multimorbidity, old age and complexity arising from pathophysiological factors such as frailty. Most of these factors are not ameliorable but highlight the challenges that healthcare professionals face when trying to avoid patients coming to harm. Of the organisational factors, problems relating to continuity and coordination of care (between providers and within primary care) were most important $(14.1 \%$ of the total). For example, the patient did not experience a 'seamless service' due to failures in coordination and sharing of information between different providers across the health and social care system, disconnect between multiple members of the primary care in the same practice and lack of care coordination as a patient transitions from secondary back to primary care. Mitigating risk for future patients could be achieved through targeting the organisational structures and processes underpinning the most frequent contributing factors.

\section{Strengths and limitations of the study}

This is one of the most comprehensive studies of avoidable harm in primary care, ${ }^{8} 10$ and one of only two records review studies we are aware of that is large enough to report on substantial numbers of significant harms. ${ }^{13}$ It is the only study of which we are aware that has reported the incidence of avoidable harm based on independent review of primary care clinical records. In terms of other potential methods of investigation, independent retrospective case note review has significant advantages over incident reports, which are more at risk of selection bias and are not well suited to accurately estimating the incidence of avoidable harm. It also has advantages over database studies because detailed examination is required of the healthcare records (including hospital correspondence), which is not possible through clinical databases. One major limitation of case note review is the onerous task of searching for and identifying important information to build a narrative, based on what is explicitly stated or from what is absent based on the clinician's knowledge of the relevant evidence-based guidelines.

We used a stratified random sampling approach to recruit 12 general practices from three geographically different regions of England, and the independent GPs involved in data collection were experienced and were given thorough training. We used a validated method for judging the avoidability of harm ${ }^{14}$ and a comprehensive validated system for classifying the underlying causes of patient harm. ${ }^{15}$ Our methodological approach used the recursive model of incident analysis and permitted us to capture the series of 'contributing incidents' that led to the final 'principal incident' prior to the patient experiencing a harmful outcome. ${ }^{25}$ This meant we could provide

Table 4 Summary of cases judged by the study team to have significant harm with at least slight to modest evidence of avoidability

Avoidability rating following moderation of all cases by the study team

\begin{tabular}{|c|c|c|c|c|c|c|}
\hline Cases & $\begin{array}{l}\text { Slight to } \\
\text { modest } \\
\text { evidence of } \\
\text { avoidability }\end{array}$ & $\begin{array}{l}\text { Possibly avoidable, } \\
<50-50, \text { but close } \\
\text { call }\end{array}$ & $\begin{array}{l}\text { Probably avoidable, } \\
>50-50 \text {, but close } \\
\text { call }\end{array}$ & $\begin{array}{l}\text { Strong } \\
\text { evidence of } \\
\text { avoidability }\end{array}$ & $\begin{array}{l}\text { Virtually } \\
\text { certain } \\
\text { evidence of } \\
\text { avoidability }\end{array}$ & Total \\
\hline $\begin{array}{l}\text { Cases from enhanced sample (first GP } \\
\text { data collector) }\end{array}$ & 16 & 19 & 18 & 14 & 0 & 67 \\
\hline $\begin{array}{l}\text { Additional cases from } 10 \% \text { sample } \\
\text { of enhanced sample (second GP data } \\
\text { collector) }\end{array}$ & 2 & 2 & 1 & 1 & 0 & 6 \\
\hline $\begin{array}{l}\text { Additional case from } 2.5 \% \text { sample } \\
\text { (not from enhanced sample) }\end{array}$ & 1 & 0 & 0 & 0 & 0 & 1 \\
\hline Total & 19 & 21 & 19 & 15 & 0 & 74 \\
\hline
\end{tabular}

GP, general practitioner. 
Table 5 Distribution of different types of primary incidents

Types of primary incident: incidents occurring proximal (chronologically) to the patient outcome

\begin{tabular}{|c|c|c|c|}
\hline & & & \\
\hline Diagnostic errors & $45(60.8)$ & $34(61.8)$ & $22(64.7)$ \\
\hline $\begin{array}{l}\text { Wrong diagnosis-original diagnosis is found to be incorrect because the } \\
\text { true cause is discovered later. }\end{array}$ & $16(21.6)$ & $13(23.6)$ & $11(32.4)$ \\
\hline $\begin{array}{l}\text { Delayed diagnosis (non-cancer) — diagnosis could have been made earlier if } \\
\text { care was evidence-based. }\end{array}$ & $21(28.4)$ & $15(27.3)$ & $10(29.4)$ \\
\hline Delayed cancer diagnosis & $8(10.8)$ & $6(10.9)$ & $1(2.9)$ \\
\hline Medication errors & $19(25.7)$ & $13(23.6)$ & $6(17.6)$ \\
\hline No drug treatment given & $4(5.4)$ & $3(5.4)$ & $2(5.9)$ \\
\hline Insufficient drug treatment given & $4(5.4)$ & $4(7.3)$ & $1(2.9)$ \\
\hline Prescribing errors & $6(8.1)$ & $4(7.3)$ & $1(2.9)$ \\
\hline Monitoring errors & $2(2.7)$ & $2(3.6)$ & $2(5.9)$ \\
\hline Adverse drug reaction & $1(1.3)$ & - & - \\
\hline Medication not commenced in a timely manner & $1(1.3)$ & - & - \\
\hline Vaccine administration & $1(1.3)$ & - & - \\
\hline Referral errors & $8(10.8)$ & $7(12.7)$ & $6(17.6)$ \\
\hline Delayed referral & $7(9.4)$ & $6(10.9)$ & $6(17.6)$ \\
\hline Referral not performed when indicated & $1(1.3)$ & $1(1.8)$ & - \\
\hline Other & $2(2.7)$ & $1(1.8)$ & - \\
\hline Patient communication not sent from secondary to primary care & $1(1.3)$ & $1(1.8)$ & - \\
\hline Incorrect test ordered & $1(1.3)$ & - & - \\
\hline Total (\%) & $74(100)$ & $55(100)$ & $34(100)$ \\
\hline
\end{tabular}

the most robust and comprehensive assessment of the patient safety incidents implicated in significant avoidable harm outcomes, as well as consider the apparent underlying events when formulating our recommendations to mitigate future risk to patients.

Only a quarter of the general practices in the stratified random sample agreed to participate, and this is a limitation from an epidemiological perspective. The most common reason cited for not participating was lack of time. Although the characteristics of the practices recruited were similar to those in England in most respects, none of the study practices received an overall CQC rating of 'inadequate' or 'requires improvement', whereas $2.6 \%$ and $9.1 \%$ (respectively) of all English practices received these ratings. If CQC ratings are associated with patient safety, then our study may underestimate the overall incidence of avoidable significant harm in English general practices. Our inter-rater reliability assessments showed that there was moderate agreement between the GPs in their identification of patients with significant health problems, and their judgements as to whether a patient had experienced avoidable significant harm. Even with our sensitivity analysis, the upper limit of our estimates of the incidence of avoidable significant harm may be an underestimate. This highlights the uncertainties of estimates of frequency of harm originating from case note reviews that rely on clinical judgement. It suggests that our study could have missed some cases of avoidable significant harm but could also have included cases that others might not consider to be 'significant' or 'avoidable'.

Through our enhanced sample, we successfully identified patients most likely to have avoidable significant harm, but the criteria we used might be difficult to replicate in other countries. We did, however, manage to identify these patients through electronic medical records, and so a similar approach should be possible in countries with comprehensive primary care electronic records. Our study was not designed to detect near misses.

\section{Comparison with other studies}

We recognise from our previous systematic reviews ${ }^{8} 10$ that comparing studies of avoidable harm is difficult because of different study designs and different ways of applying definitions of avoidable harm. One key difference between our study and almost all previous studies is that we report the incidence of avoidable harm rather than the prevalence (per consultation). Our approach allows for a clearer estimate of the public health burden of avoidable harm while also recognising that some harms, especially in a primary care setting, may occur over several consultations (eg, delayed diagnosis). Also, we have focused specifically on significant harm (such as a clinically important delay in cancer diagnosis) to ensure that our findings reflect 
30-week delay in diagnosing throat cancer (avoidability rating: 5, strong evidence of avoidability)

A middle-aged patient attended the general practitioner (GP) with a hoarse voice and difficulty swallowing. He reported that his mouth felt like the time he had thrush, which required a referral to a gastroenterologist for an endoscopy, and it eventually settled with an antifungal medication. In the medical records, the GP described signs of oral thrush in the mouth and wrote, 'if does not settle, consider oral treatment or referral back to gastroenterologist'. Over the next 19 weeks, the patient returned, with six visits to the original and different GPs, with on and off 'red flag' symptoms that were either improving or worsening or of varying intensity (hoarseness, swallowing issues, odd breathing pattern, difficulty talking and sensation of a lump in throat) and each time was given a course of antifungal medication. From week 12, the medical records describe 'food getting stuck'. At week 15, a referral for endoscopy was made and the patient was seen 1 week later. At this point, the patient informed the gastroenterologist he was losing weight. No abnormalities were seen on endoscopy, and the patient was told to go back to his GP and have his hoarse voice investigated further (with the same advice in a letter to the GP). Four weeks later, the patient was seen by the GP and a non-urgent referral to ears, nose and throat (ENT) was made. At week 30, the patient was seen by ENT, and a rare type of neck cancer was diagnosed requiring chemotherapy.

Seven-year delay in diagnosis of prostate cancer (avoidability rating: 4; probably avoidable, more than 50:50, but close call)

An elderly patient with type 2 diabetes mellitus attended a nurse appointment stating that he was experiencing nocturnal frequency. It was suspected this was due to poorly controlled diabetes, and amendments to his medication regime were made. Six weeks later, the patient had a telephone consultation with the GP since he was concerned about weight loss, a loss of appetite, increased urinary frequency and night cramps. He was booked with the GP for a face-to-face consultation the following day. It was also noted he had a weight loss of $2-3 \mathrm{~kg}$; he was urinating at least five to six times per night; and he felt nauseous. The GP felt the signs and symptoms were related to poorly controlled diabetes and arranged for the patient to be reviewed by the practice nurse. Over the next week, blood tests (glycosylated haemoglobin and 'urea and electrolytes' (U\&E)) and urine analysis were undertaken, and his antihyperglycaemic medications were amended. The nurse followed up the patient up a few days later, where a further drop in weight was noted. The patient reported some improvement in symptoms since he was now getting up at night to pass urine four instead of six times. The nurse advised a follow-up appointment with the GP, which did not occur until 4 weeks later. At this time, the GP noted that 7 years previously the patient had a raised prostate-specific antigen (PSA). However, the patient had been unable to tolerate a biopsy for a definitive diagnosis, so 6 monthly PSA testing was advised; however, the patient did not have a follow-up PSA in the subsequent 7-year period. On noting this, the GP advised the patient to have a PSA test which was undertaken 3 weeks later. The PSA measured very high (>100 $\mathrm{ng} / \mathrm{mL}$ ). The patient had a GP appointment 1 week later when he was informed his PSA was raised. An urgent 'suspected cancer' referral was made. He was seen by a urologist the following week and diagnosed with localised prostate cancer requiring a transurethral resection of the prostate.

\section{6-month delay in diagnosing non-insulin-dependent diabetes mellitus (avoidability rating: 3; possibly avoidable, less than 50-50, but close call)}

An impaired fasting glucose was identified in a middle-aged patient and was followed up with a glucose tolerance test (GTT). The patient was seen by GP (A) soon after and was informed the GTT revealed an impaired glucose tolerance and was given dietary and lifestyle advice. The patient was told to have a repeat test 4 months later. The patient was seen 4 months later by a different GP (B); however, the focus of the consultation was on yellow sclerae and liver function tests (LFTs) were ordered. A test to assess diabetes was not requested. The patient presented 2 months later with weight loss, and GP (B) referred the patient for an endoscopy and a repeat LFT. A follow-up telephone call 1 month later occurred to discuss the LFTs with GP (B). Three months later, the patient presented to GP (B) with tiredness and fatigue. Again, blood tests were requested but did not include tests for diabetes. Six months later, a blood glucose was undertaken as part of an annual review, and following two fasting blood glucose tests 1 week apart, poorly controlled non-insulin-dependent diabetes mellitus was diagnosed.

Four-month delay in referral for an ischaemic limb (avoidability rating: 5, strong evidence of avoidability) A patient in his early 60 s stubbed his big toe 3 weeks prior to attending a nurse appointment at the general practice. The patient was known to have cardiovascular disease, including hypertension (prescribed two antihypertensives) and raised cholesterol (prescribed a statin). The nurse noted the toe was bruised, painful, red and had a foul odour. The patient was prescribed antibiotics for a presumed infection, and a referral was made to podiatry for removal of an associated ingrowing toenail. Four weeks later, a podiatrist was unable to detect a dorsalis pedis or posterior tibial pulse in the affected foot, and the patient was advised to see a GP urgently. The patient was reviewed by the GP, and a referral to a vascular surgeon was discussed but not made. Instead, a further consultation with the same GP in 4 weeks was agreed, with regular nursing 


\section{Box 2 Continued}

reviews of wound healing in the interim. At the first follow-up nurse review 1 week later, the nurse noted that the toe was healing, but there were no pulses with the Doppler scan, and that the patient informed the nurse he needed to sleep with the foot outside the bed because it was so painful. The GP saw him 3 days later and decided to make a non-urgent vascular referral, but the letter was not sent to the vascular surgeons for 6 weeks. The patient was seen in a vascular clinic nearly 4 months after the podiatrist noted absent pulses and was informed that he had critical leg ischaemia and needed surgery. He underwent a right superficial femoral artery and posterior tibial artery (PTA) stent 4 weeks later. Some 9 months later, he required amputation of his big toe and second digit.

\section{Long-term nephrotoxic medications in older adults}

We observed two cases where patients with known reduced kidney function were receiving long-term potentially nephrotoxic drugs. One of the patients was prescribed naproxen 'as required' for gout but received a two times per day monthly supply for $>12$ months while concurrently receiving long-term nitrofurantoin. A hospital admission for acute-onchronic kidney injury was required (avoidability rating: 5 , strong evidence of avoidability).

Another patient was taking lithium and should have had 3 monthly U\&E blood tests to monitor their kidney function. This did not happen for 15 months, and the patient was admitted with acute kidney injury (avoidability rating: 4; probably avoidable, more than 50:50, but close call).

a health burden that is unquestionably of importance to patients, the public, clinicians and policy makers.

The only study we are aware of that was of a similar large size to ours, while also reporting on severity, was from a convenience sample of 48 health centres in Spain with health professionals reporting any incidents causing harm. ${ }^{13}$ From 96047 consultations, 773 harms were detected with 46 of these considered 'severe'. Of all the harms, $64.3 \%$ were considered preventable, and applying this percentage to the severe harms suggests a prevalence of 30.8 severe harms per 100000 consultations. It is not possible to directly compare this with the incidence figures from our study (where the same harm may have been apparent across several consultations over the course of the 12 months), but the overall rates of significant harm are probably not widely dissimilar.

There is considerable variation in studies reporting categories of avoidable harm as well as contributory factors. Nevertheless, our findings are in keeping with a systematic review that found that diagnostic errors were among the most important causes of avoidable harm, ${ }^{10}$ and a review of the global burden of diagnostic errors in primary care, ${ }^{26}$ while the systematic review ${ }^{10}$ (and other studies) has highlighted the importance of prescribing errors. ${ }^{13}$ In relation to diagnostic delay in cancer, a recent study has highlighted that in almost half of the cases, this is attributable to primary care ${ }^{27}$ with problems with clinical appraisal of the patient and referral being particularly important. Our study has specifically highlighted the importance of delays in making a referral, ${ }^{15}{ }^{23}$ and this has been highlighted as an important problem by the Institute for Healthcare Improvement. ${ }^{28}$ In comparison with other studies, ours is unusual in reporting such a high level of patient factors contributing to patient harm. While many of these cannot be considered the reason for the harm being avoidable, the findings suggest that factors such as multimorbidity, frailty and complex presentations may make it more difficult for clinicians to make timely and accurate diagnosis and avoid medication errors. In relation to contributory factors that are avoidable, our findings are in keeping with other studies that have highlighted organisational issues and communication problems. ${ }^{812} 29$

\section{Implications for clinicians and policy makers}

This study has estimated the incidence of significant harm in English primary care considered at least probably avoidable, which translates to three to four cases per year for an average general practice of 8000 patients. Efforts to make improvements should focus on addressing the structures and processes underpinning the identified patient, clinician and organisational contributing factors. For example, better organisation of key systems (eg, referrals, test result management, identifying non-adherence) and related administration could have prevented most incidents. Some of the earliest patient safety studies carried out in primary care over two decades ago pointed to administrative failures, such as the mismanagement of test results, as the root cause of the the most common incidents concerning diagnosis and medication, ${ }^{30-32}$ and an Australian study concluded about $70 \%$ of incidents were related to processes of providing healthcare, rather than gaps in the knowledge and skills of health professionals. ${ }^{11}$ The current study provides considerable insights into the ameliorable contributory factors associated with avoidable significant harm in primary care, which in turn have generated the following suggestions for improvement.

More effective implementation of existing information technology solutions could ensure that planned action such as referrals take place in a timely way. ${ }^{26}$ Enhanced team coordination and communication could ensure that patients are seen (or have necessary 
Box 3 Underlying incidents resulting in

delayed diagnoses (history taking, examination, investigation, communication and referral)

- Incomplete history taking (one case), for example, not enquiring about red flags and not documenting salient negatives, inaccurate medical records (two cases), and inadequate documentation of care delivered (one case).

- Absent or delayed physical examination (five cases), for example, advising patient to book another visit to undertake a pelvic examination.

- Not ordering correct investigations (three cases), for example, no follow-up or investigations ordered for an older adult with a 3-week history of diarrhoea with blood and mucus; the patient eventually required an emergency admission, and Crohn's disease was diagnosed.

- Failing to order a necessary investigation (one case), for example, not testing for diabetes mellitus when presenting with lower urinary tract symptoms.

- Inappropriate responses to laboratory (three cases) or imaging (one case) investigations, for example, (1) not recognising the cut-off for diagnosing type 2 diabetes, (2) not arranging a follow-up chest X-ray (that had been advised by a radiologist) in a patient with an opacity seen on serial radiographs (this resulted in a delay in referral to respiratory medicine for an eventual diagnosis of lung cancer).

- Transfer of information about the patient, which included delays in the communication being sent (two cases) or not sent at all by secondary care (one case), or a communication received but not actioned in primary care (three cases).

- Incorrect advice being given to the patient (one case), for example, patient with insulin-dependent diabetes not given information about how to prepare for an endoscopy and the general practitioner did not inform secondary care the patient was diabetic.

- Delayed referral (seven cases), referral not made (one case) or referral sent to the wrong location.

investigations) or that they are recalled for follow-up investigations or assessment when needed. Currently, it is largely down to individual primary care teams and individual healthcare practitioners to develop their own strategies. Without stifling innovation, however, it might be helpful to model 'what best practice looks like' in relation to preventing patients from coming to harm. Interventions like the 'QRISK3-2018' algorithm to calculate a person's risk of developing a 'heart attack' or stroke are now commonly integrated into electronic health record systems and used by clinicians to explain and manage risk and support patient decision-making. ${ }^{33}$ In a similar way, the factors implicated in patient safety incidents that we have identified might be considered as signals for future algorithms for development and validation, either to flag up patients for timely clinical review to mitigate current risk levels or to proactively detect risks of future unsafe care.

Our study suggests that lack of continuity of care may contribute to avoidable significant harm in some cases. ${ }^{34}$ Recent systematic reviews suggest that low continuity of care is associated with a higher risk of mortality across different healthcare settings ${ }^{35}$ and specifically in general practice. ${ }^{36}$ In some cases in our study, follow-up by the same primary healthcare practitioner could have been helpful to enable earlier recognition of the progression of a serious health problem. In other cases, better 'informational continuity ${ }^{37}$ could have helped to ensure that the assessment and suggested follow-up plans from a previous consultation better informed the next consultation. This should be facilitated by electronic health records, but we found several examples where recommendations from one consultation were not acted on in a subsequent consultation involving a different healthcare practitioner. Nevertheless, high levels of personal continuity may not always be best for patients. A recent qualitative study showed a mixed picture in terms of patients' perceptions of whether personal continuity improved safety, or not, ${ }^{38}$ while a crosssectional ecological study found that general practices that appeared to have high levels of personal continuity did fewer urgent referrals ${ }^{39}$; this does not necessary mean they were less safe, but it is a potential cause for concern.

Some of the cases of avoidable significant harm in our study were associated with GPs having too many problems to deal with adequately in a single consultation, with significant health problems not detected early enough because of lack of effective and timely clinical history taking, examination or investigation. Some of the contributory factors associated with patient behaviours may have resulted from their concerns being unrecognised or unresolved, as highlighted in a study of missed opportunities in cancer diagnosis. ${ }^{40}$ When such incidents occur in general practice, it is essential that practice teams know how to generate learning from the incident, including how to identify vulnerabilities in their existing structures and processes, and feel confident to plan and test changes that could achieve improved outcomes for future patients. ${ }^{41}$ The introduction of quality improvement domains into 2019/2020 Quality and Outcomes Framework by NHS England represents a promising commitment for supporting practices to learn about and develop their approach to systems improvement ${ }^{42}$ as does the 2019 NHS Patient Safety Strategy. ${ }^{43}$

\section{CONCLUSION}

There is likely to be a substantial burden of avoidable significant harm attributable to primary care in England with diagnostic error accounting for most harms, followed by medication error and 
Table 6 Distribution of contributory factors

Types of contributory factor: circumstances, actions or influences which are thought to have played a part in the origin or development, or to increase the risk, of a patient safety incident $^{46}$

\section{At least slight to} modest evidence of avoidability, n (\%)
At least possible evidence of avoidability, $\mathrm{n}(\%)$
At least probable evidence of avoidability, $\mathrm{n}(\%)$

\begin{tabular}{|c|c|c|c|c|c|c|}
\hline Patient factors & 82 & (71.9) & 59 & $(69.4)$ & 32 & $(68.1)$ \\
\hline Multimorbidity: patient has two or more chronic medical conditions & 20 & $(17.5)$ & 15 & $(17.6)$ & 11 & $(23.4)$ \\
\hline Comorbidity: the presence of one or more additional diseases & 8 & $(7.0)$ & 5 & $(5.9)$ & 3 & $(6.4)$ \\
\hline Rare presentation: an uncommon pattern of signs or symptoms & 8 & (7.0) & 5 & $(5.9)$ & 3 & $(6.4)$ \\
\hline Previous medical/medication history & 8 & (7.0) & 5 & $(5.9)$ & 3 & (6.4) \\
\hline Patient age & 7 & (6.1) & 6 & (7.1) & 3 & (6.4) \\
\hline $\begin{array}{l}\text { Pathophysiological factors: the patient's physical and medical well- } \\
\text { being and health inclusive of frailty }\end{array}$ & 6 & (5.3) & 5 & (5.9) & 3 & (6.4) \\
\hline $\begin{array}{l}\text { Clinician perception of patient behaviours: the way in which patients } \\
\text { or caregivers act towards clinicians }\end{array}$ & 6 & (5.3) & 5 & (5.9) & 1 & $(2.1)$ \\
\hline $\begin{array}{l}\text { Response to medical advice: patient does not appear to follow the } \\
\text { advice or instructions given by the clinician }\end{array}$ & 6 & (5.3) & 4 & (4.7) & - & \\
\hline $\begin{array}{l}\text { Complex agenda: patient presents with multiple issues in a single } \\
\text { consultation }\end{array}$ & 4 & (3.5) & 3 & (3.5) & 1 & $(2.1)$ \\
\hline $\begin{array}{l}\text { Medication taking: patient does not appear to take medication as } \\
\text { prescribed }\end{array}$ & 2 & (1.8) & 2 & (2.4) & - & \\
\hline Clinical history taking: problems with eliciting relevant information & 2 & $(1.8)$ & 1 & $(1.2)$ & 1 & $(2.1)$ \\
\hline Language: patient unable to communicate in English & 2 & $(1.8)$ & 2 & (2.4) & 2 & $(4.3)$ \\
\hline $\begin{array}{l}\text { Disability: a physical or mental condition that limits a person's } \\
\text { movements, senses or activities }\end{array}$ & 2 & $(1.8)$ & 1 & $(1.2)$ & 1 & $(2.1)$ \\
\hline Does not leave the house or home & 1 & (0.9) & - & & - & \\
\hline Staff factors & 8 & $(7.0)$ & 7 & $(8.2)$ & 5 & $(10.6)$ \\
\hline Inadequate knowledge/skill set & 6 & (5.3) & 6 & (7.1) & 4 & $(8.5)$ \\
\hline Mistake & 2 & $(1.8)$ & 1 & $(1.2)$ & 1 & $(2.1)$ \\
\hline Organisational issues & 24 & $(21.1)$ & 19 & $(22.4)$ & 10 & $(21.3)$ \\
\hline $\begin{array}{l}\text { Continuity of care across system: problem with the delivery of a } \\
\text { 'seamless service' through integration, coordination and sharing of } \\
\text { information between different providers }\end{array}$ & 8 & (7.0) & 8 & (9.4) & 4 & $(8.5)$ \\
\hline $\begin{array}{l}\text { Continuity of care within primary care: seen by multiple members of } \\
\text { the team within the same practice }\end{array}$ & 6 & (5.3) & 3 & (3.5) & 1 & $(2.1)$ \\
\hline $\begin{array}{l}\text { Continuity of care between secondary and primary care: lack of } \\
\text { coordinated care }\end{array}$ & 2 & $(1.8)$ & 1 & $(1.2)$ & - & \\
\hline $\begin{array}{l}\text { Protocols/policies/standards/guidelines inadequate, inefficient, } \\
\text { absent or not available } \\
\text { (specific problems noted below) }\end{array}$ & 2 & (1.8) & 1 & $(1.2)$ & 1 & $(2.1)$ \\
\hline Investigations & 2 & (1.8) & 2 & (2.4) & 1 & $(2.1)$ \\
\hline Repeat prescribing & 1 & $(0.9)$ & 1 & $(1.2)$ & 1 & $(2.1)$ \\
\hline Referral & 1 & $(0.9)$ & 1 & $(1.2)$ & - & \\
\hline Locum or agency staff & 1 & (0.9) & 1 & $(1.2)$ & 1 & $(2.1)$ \\
\hline Waiting lists for 'urgent' referrals & 1 & $(0.9)$ & 1 & $(1.2)$ & 1 & $(2.1)$ \\
\hline Total (\%) & 114 & $(100)$ & 85 & $(100)$ & 47 & $(100)$ \\
\hline
\end{tabular}

delays in making a referral once a referral decision had been made. Based on the contributory factors we found, improvements could be made through more effective implementation of existing information technology, enhanced team coordination and communication, and greater personal and informational continuity of care.

\section{Author affiliations}

'Division of Primary Care, School of Medicine, Faculty of Medicine and Health Sciences, University of Nottingham, Nottingham, UK
${ }^{2}$ NIHR Greater Manchester Patient Safety Translational Research Centre, Faculty of Biology, Medicine and Health, University of Manchester, Manchester, UK

${ }^{3} \mathrm{NIHR}$ RDS for the East Midlands, Faculty of Medicine and Health Sciences, University of Nottingham, Nottingham, UK

${ }^{4}$ Division of Pharmacy and Optometry, School of Health Sciences, Faculty of Biology, Medicine and Health, University of Manchester, Manchester, UK ${ }^{5}$ Division of Pharmacy Practice and Policy, School of Pharmacy, Faculty of Sciences, University of Nottingham, Nottingham, UK

${ }^{6}$ Division of Population Medicine, School of Medicine, Cardiff University, Cardiff, UK

${ }^{7}$ School of Health Sciences, Faculty of Medicine and Health Sciences, University of Nottingham, Nottingham, UK 
${ }^{8}$ Birmingham Clinical Trials Unit, College of Medical and Dental Sciences, University of Birmingham, Birmingham, UK

${ }^{9}$ PRIMIS, School of Medicine, Faculty of Medicine and Health Sciences, University of Nottingham, Nottingham, UK

${ }^{10}$ Usher Institute of Population Health Sciences and Informatics, College of Medicine and Veterinary Medicine, The University of Edinburgh, Edinburgh, UK

${ }^{11}$ School of Health and Social Sciences, Edinburgh University, Edinburgh, UK

${ }^{12}$ Centre for Primary Care, Division of Population Health, Health Services Research \& Primary Care, School of Health Sciences, Faculty of Biology, Medicine and Health, University of Manchester, Manchester, UK

\section{Twitter Anthony J Avery@tonyavery1}

Acknowledgements We thank Dr Christine Johnson and others who helped us to recruit the general practitioners (GPs) for the retrospective case note review. We also thank all of the practices that willingly took part in the retrospective case note review study; they were all very welcoming to the GPs who undertook the data collection, and provided space, access to computers and support to allow them to undertake their work. We are particularly indebted to the GPs who did the data collection as they were highly committed to the study, and many of them went the extra mile in terms of fitting in extra data collection sessions to enable us to complete the study within the time frame agreed. In particular, we thank Dr Richard Thomas for providing most of the training for the GPs. We thank Ed Longridge for running most of the baseline computer searches in the practices and for collecting data to allow us to calculate 'patient-years' (the denominator for our study). We thank Dr Sukhmeet Panesar for advice at the development stage of the project, particularly concerning literature on avoidable harm. We are extremely grateful to the members of our external advisory group (chaired by Professor Charles Vincent and including Professor Susan Dovey, Dr Frances Healey (funder representative) and Professor Gordon Schiff), who gave very helpful advice throughout the study and were particularly helpful in terms of the interpretation of our findings. We also thank members of the East Midlands Academic Health Science Network PPI Senate and the Greater Manchester Patient Safety Translational Research Centre and Health Innovation Manchester Patient Experience Group for reviewing the findings and providing helpful comments from the perspective of members of the public.

Contributors All authors made a substantial contribution to the conception or design of the work; or the acquisition, analysis or interpretation of data for the work. Specifically, AJA, ACh, AC-S, AD, AE, AS, DMA, HPE, MJB, SMC, SA and SR conceived the study; AJA, ACh, AC-S, AD, AE, AS, DMA, HPE, JL, MJB, PS, RM, SMC, SA and SR designed the study; AJA, AC-S, CS, DMA, SMC and SR recruited the general practitioner (GP) reviewers and practices; AJA, AC-S, AE, CS and HPE trained the GP reviewers; AJA, ACh, ACo, AC-S, AD, AE, CS, DMA, HPE, JL, MJB, SMC, SH and SR designed the data collection process; AJA, ACo, AC-S, AE, $\mathrm{BB}, \mathrm{HW}$ and $\mathrm{SH}$ processed the data; AJA, ACo, AC-S, AE, $\mathrm{HW}$, and $\mathrm{SH}$ contributed to team judgements of avoidability of harm; AJA, ACo, AC-S, AE, BB and HW analysed the data, and all authors were involved in interpretation of the data; AJA, AC-S, AE, AS, BB, CS, DMA and SMC drafted the paper and all authors revised it critically for important intellectual content; all authors gave the final approval of the version to be published and agreed to be accountable for all aspects of the work in ensuring that questions related to the accuracy or integrity of any part of the work are appropriately investigated and resolved. AJA is the guarantor for the paper and accepts full responsibility for the work and/or the conduct of the study, had access to the data and controlled the decision to publish.

Funding This paper is based on independent research commissioned and funded by the National Institute for Health Research (NIHR) Policy Research Programme ('Understanding the Nature and Frequency of Avoidable Harm in Primary Care', Ref: PR-R11-0914-11001). General practitioner time was funded by the NIHR Greater Manchester Patient Safety Translational Research Centre (NIHR Greater Manchester PSTRC).
Disclaimer The views expressed in the publication are those of the authors and not necessarily those of the National Institute for Health Research or the Department of Health and Social Care.

Competing interests None declared.

\section{Patient consent for publication Not required.}

Ethics approval The study had NHS research ethics committee approval and was granted a favourable opinion by the East Midlands Nottingham 2 Research Ethics Committee on 15 January 2016 (reference: 15/EM/0411) and Confidentiality Advisory Group approval for access to medical records without consent under section 251 of the NHS Act 2006 on 11 April 2016 (reference: 15/CAG/0182). Research and development approval was obtained for the Clinical Commissioning Groups, where the study occurred.

Provenance and peer review Not commissioned; externally peer reviewed.

Data availability statement Data are available upon reasonable request. Anonymised summary data extracted from patient records regarding the avoidable harms detected in this study will be available upon reasonable request.

Supplemental material This content has been supplied by the author(s). It has not been vetted by BMJ Publishing Group Limited (BMJ) and may not have been peer-reviewed. Any opinions or recommendations discussed are solely those of the author(s) and are not endorsed by BMJ. BMJ disclaims all liability and responsibility arising from any reliance placed on the content. Where the content includes any translated material, BMJ does not warrant the accuracy and reliability of the translations (including but not limited to local regulations, clinical guidelines, terminology, drug names and drug dosages), and is not responsible for any error and/or omissions arising from translation and adaptation or otherwise.

Open access This is an open access article distributed in accordance with the Creative Commons Attribution Non Commercial (CC BY-NC 4.0) license, which permits others to distribute, remix, adapt, build upon this work noncommercially, and license their derivative works on different terms, provided the original work is properly cited, appropriate credit is given, any changes made indicated, and the use is noncommercial. See: http://creativecommons.org/licenses/by-nc/4. $0 /$.

\section{ORCID iDs}

Anthony J Avery http://orcid.org/0000-0001-7591-4438

Matthew J Boyd http://orcid.org/0000-0003-2997-5090

Aziz Sheikh http://orcid.org/0000-0001-7022-3056

\section{REFERENCES}

1 World Health Organization,, Organisation for Economic CoOperation and Development,, The World Bank. Delivering quality health services: a global imperative for universal health coverage, 2018. Available: https://apps.who.int/iris/handle/ 10665/272465 [Accessed 17 Aug 2020].

2 Sheikh A, Bates DW. Iatrogenic harm in primary care. Harvard Health Policy Review 2014;14:4-8.

3 NHS Digital. Appointments in general practice, 2018. Available: https://digital.nhs.uk/data-and-information/ publications/statistical/appointments-in-general-practice/oct2018 [Accessed 17 Aug 2020].

4 Berwick DM, Shojania KG, Atchinson BK. Free from harm: accelerating patient safety improvement fifteen years after to err is human. Boston, MA: National Patient Safety Foundation, 2015.

5 Sheikh A, Panesar SS, Larizgoitia I, et al. Safer primary care for all: a global imperative. Lancet Glob Health 2013;1:e182-3.

6 World Health Organization. Safer primary care-A global challenge. Geneva: WHO, 2012. 
7 Slawomirski L, Auraaen A, Klazinga N. The economics of patient safety in primary and ambulatory care: flying blind. OECD. Available: https://www.oecd.org/health/health-systems/ The-Economics-of-Patient-Safety-in-Primary-and-AmbulatoryCare-April2018.pdf [Accessed 17 Aug 2020].

8 Panesar SS, deSilva D, Carson-Stevens A, et al. How safe is primary care? A systematic review. BMJ Qual Saf 2016;25:544-53.

9 Cresswell KM, Panesar SS, Salvilla SA, et al. Global research priorities to better understand the burden of iatrogenic harm in primary care: an international Delphi exercise. PLoS Med 2013;10:e1001554.

10 Panagioti M, Khan K, Keers RN, et al. Prevalence, severity, and nature of preventable patient harm across medical care settings: systematic review and meta-analysis. BMJ 2019;366:14185.

11 Makeham MAB, Kidd MR, Saltman DC, et al. The threats to Australian patient safety (TAPS) study: incidence of reported errors in general practice. Med J Aust 2006;185:95-8.

12 Gaal S, Verstappen W, Wolters R, et al. Prevalence and consequences of patient safety incidents in general practice in the Netherlands: a retrospective medical record review study. Implement Sci 2011;6:37.

13 Aranaz-Andrés JM, Aibar C, Limón R, et al. A study of the prevalence of adverse events in primary healthcare in Spain. Eur J Public Health 2012;22:921-5.

14 Carson-Stevens A, Campbell S, Bell BG, et al. Identifying 'avoidable harm' in family practice: a RAND/UCLA Appropriateness Method consensus study. BMC Fam Pract 2019;20:134

15 Carson-Stevens A, Hibbert P, Williams H, et al. Characterising the nature of primary care patient safety incident reports in the England and Wales national reporting and learning system: a mixed-methods agenda-setting study for general practice. Health Serv Deliv Res 2016;4:1-76.

16 Bell BG, Campbell S, Carson-Stevens A, et al. Understanding the epidemiology of avoidable significant harm in primary care: protocol for a retrospective cross-sectional study. BMJ Open 2017;7:e13786.

17 Hogan H, Healey F, Neale G, et al. Preventable deaths due to problems in care in English acute hospitals: a retrospective case record review study. BMJ Qual Saf 2012;21:737-45.

18 Tsang C, Bottle A, Majeed A, et al. Adverse events recorded in English primary care: observational study using the general practice research database. Br J Gen Pract 2013;63:e534-42.

19 Barber ND, Alldred DP, Raynor DK, et al. Care homes' use of medicines study: prevalence, causes and potential harm of medication errors in care homes for older people. Qual Saf Health Care 2009;18:341-6.

20 King's Fund. Parr combined predictive model final report. Available: http://www.kingsfund.org.uk/sites/files/kf/field/field document/PARR-combined-predictive-model-final-reportdec06.pdf [Accessed 18 Aug 2020].

21 Duerden M, Avery T, Payne R. Polypharmacy and medicines optimisation: making it safe and sound. London: The King's Fund, 2013.

22 Lowy A, Brazier J, Fall M, et al. Quality of minor surgery by general practitioners in 1990 and 1991. Br J Gen Pract 1994;44:364-5.

23 Study A. Patient safety in primary health care. Madrid: Ministry of Health and Consumer Affairs, 2008.

24 Carson-Stevens A, Hibbert P, Avery A, et al. A cross-sectional mixed methods study protocol to generate learning from patient safety incidents reported from general practice. BMJ Open 2015;5:e009079.

25 Hibbert P, Runciman W, Deakin A. A recursive model of incident analysis. Adelaide: Australian Patient Safety Foundation, 2007.

26 Singh H, Schiff GD, Graber ML, et al. The global burden of diagnostic errors in primary care. BMJ Qual Saf 2017;26:484-94.

27 Swann R, Lyratzopoulos G, Rubin G, et al. The frequency, nature and impact of GP-assessed avoidable delays in a population-based cohort of cancer patients. Cancer Epidemiol 2020;64:101617.

28 Institute for Healthcare Improvement. Closing the loop: a guide to safer ambulatory referrals in the her era. 2017. available online at. Available: http://www.ihi.org/resources/ Pages/Publications/Closing-the-Loop-A-Guide-to-SaferAmbulatory-Referrals.aspx [Accessed 16 Aug 2020].

29 Makeham M, Dovey S, Runciman W, et al. Methods and measures used in primary care patient safety research. Geneva: World Health Organization, 2008.

30 Wahls T, Haugen T, Cram P. The continuing problem of missed test results in an integrated health system with an advanced electronic medical record. Jt Comm J Qual Patient Saf 2007;33:485-92.

31 Reid S, Miller G, Britt H, et al. Breast cancer--could it have been diagnosed earlier? Aust Fam Physician 1996;25:1752-3.

32 Cox SJ, Holden JD. A retrospective review of significant events reported in one district in 2004-2005. Br J Gen Pract 2007;57:732-6.

33 Hippisley-Cox J, Coupland C, Brindle P. Development and validation of QRISK3 risk prediction algorithms to estimate future risk of cardiovascular disease: prospective cohort study. BMJ 2017;357:j2099.

34 Maarsingh OR, Henry Y, van de Ven PM, et al. Continuity of care in primary care and association with survival in older people: a 17-year prospective cohort study. Br J Gen Pract 2016;66:e531-9.

35 Pereira Gray DJ, Sidaway-Lee K, White E, et al. Continuity of care with Doctors-a matter of life and death? A systematic review of continuity of care and mortality. BMJ Open 2018;8:e021161.

36 Baker R, Freeman GK, Haggerty JL, et al. Primary medical care continuity and patient mortality: a systematic review. $\mathrm{Br} \mathrm{J}$ Gen Pract 2020;70:e600-11.

37 Duffy S, Lee TH. In-Person health care as option B. N Engl J Med 2018;378:104-6.

38 Murphy M, Salisbury C. Relational continuity and patients' perception of GP trust and respect: a qualitative study. $\mathrm{Br} \mathrm{J}$ Gen Pract 2020;70:e676-83.

39 Lyratzopoulos G, Mendonca SC, Gildea C, et al. Associations between diagnostic activity and measures of patient experience in primary care: a cross-sectional ecological study of English general practices. Br J Gen Pract 2018;68:e9-17.

40 Amelung D, Whitaker KL, Lennard D, et al. Influence of doctor-patient conversations on behaviours of patients presenting to primary care with new or persistent symptoms: a video observation study. BMJ Qual Saf 2020;29:198-208.

41 Carson-Stevens A, Donaldson L. Reporting and learning from patient safety incidents in general practice: a practical guide. Royal College of general practitioners. Available: http://www. rcgp.org.uk/-/media/Files/CIRC/Patient-Safety/Reporting-andlearning-from-patient-safety-incidents.ashx?la=en [Accessed 18 Aug 2020]. 


\section{Original research}

42 England NHS. General medical services (GMS) contract quality and outcomes framework (QOF), guidance for GMS contract 2019/2020 in England, 2019/20. Available: https:// www.england.nhs.uk/wp-content/uploads/2019/05/gmscontract-qof-guidance-april-2019.pdf [Accessed 18 Aug 2020].

43 NHS England and NHS Improvement. The NHS patient safety strategy: safer culture, safer systems, safer patients, 2019. Available: https://improvement.nhs.uk/ documents/5472/ 190708_Patient_Safety_Strategy_for_website_v4.pdf [Accessed 18 Aug 2020].
44 World Health Organization. The conceptual framework for the International classification for patient safety. Geneva: World Health Organization, 2009.

45 Jones JW. The healthcare professional and the Bolam test. $\mathrm{Br}$ Dent J 2000;188:237-40.

46 McKay J, Bradley N, Lough M, et al. A review of significant events analysed in general practice: implications for the quality and safety of patient care. BMC Fam Pract 2009;10:61. 